\title{
Correction to: The MAVEN Radio Occultation Science Experiment (ROSE)
}

\author{
Paul Withers $^{1} \cdot$ M. Felici ${ }^{2}$ M. Mendillo ${ }^{1}$ - L. Moore ${ }^{2}$. \\ C. Narvaez ${ }^{2}$ M.F. $\operatorname{Vogt}^{2}$ • K. Oudrhiri ${ }^{3}$ - D. Kahan ${ }^{3}$. \\ B.M. Jakosky ${ }^{4}$
}

Published online: 29 June 2020

(C) Springer Nature B.V. 2020

\section{Correction to: Space Sci. Rev. (2020) 216: 61 \\ https://doi.org/10.1007/s11214-020-00687-6}

This article unfortunately was published without the Electronic Supplementary Material mentioned in the article text. With the publication of this correction the ESM "radio_occ_mvn_ssrlikev32.pro" is now available online.

Publisher's Note Springer Nature remains neutral with regard to jurisdictional claims in published maps and institutional affiliations.

This is a Special Communication, linked to the Topical Volume on 'The Mars Atmosphere and Volatile Evolution (MAVEN) Mission' published in Space Science Reviews (https://link.springer.com/journal/11214/195/1)

The original article can be found online at https://doi.org/10.1007/s11214-020-00687-6

Electronic supplementary material The online version of this article (https://doi.org/10.1007/s11214-020-00714-6) contains supplementary material, which is available to authorized users.

$\triangle$ P. Withers

withers@bu.edu

1 Department of Astronomy/Center for Space Physics, Boston University, Boston, MA, USA

2 Center for Space Physics, Boston University, Boston University, Boston, MA, USA

3 NASA Jet Propulsion Laboratory, Pasadena, CA, USA

4 Laboratory for Atmospheric and Space Physics, University of Colorado Boulder, Boulder, CO, USA 